\title{
Effects of curcumin on the apoptosis of cardiomyocytes and the expression of NF-KB, PPAR- $\gamma$ and Bcl-2 in rats with myocardial infarction injury
}

\author{
FENG-HUA LV ${ }^{1}$, HONG-LEI YIN ${ }^{1}$, YI-QUN HE ${ }^{2}$, HUI-MIN WU ${ }^{3}$, \\ JUAN KONG $^{3}$, XIAO-YAN CHAI ${ }^{1}$ and SU-RONG ZHANG ${ }^{1}$ \\ ${ }^{1}$ Department of Cardiology, The First Teaching Hospital of Xinxiang Medical College; \\ ${ }^{2}$ Department of Psychosomatic Medicine, The Second Teaching Hospital of Xinxiang Medical College; \\ ${ }^{3}$ Department of Cardiology, The Third Teaching Hospital of Xinxiang Medical College, Weihui, Henan 453100, P.R. China
}

Received May 9, 2015; Accepted September 7, 2016

DOI:: 10.3892/etm.2016.3858

\begin{abstract}
Curcumin is a natural polyphenol with powerful antioxidant and anti-inflammatory properties. The present study evaluated the protective effect of curcumin on myocardial injury in rats as well as the mechanisms underlying these effects, and examined the expression of nuclear factor- $\kappa \mathrm{B}$ $(\mathrm{NF}-\kappa \mathrm{B})$, peroxisome proliferator-activated receptor- $\gamma$ (PPAR- $\gamma$ ) and B-cell leukemia/lymphoma-2 (Bcl-2) following myocardial infarction. A rat model of myocardial infarction was successfully established. Hematoxylin and eosin staining showed cellular atrophy and hyperchromatic cytoplasm in the myocardial infarction area. The myocardial cells displayed lysis and breakage of cardiac muscle fibers, karyopyknosis and karyorrhexis associated with infiltration of inflammatory cells and proliferation of fibrous tissue. Curcumin treatment at a dosage of $150 \mathrm{mg} / \mathrm{kg} /$ body weight resulted in an increase in surviving cells, fewer apoptotic cells, decreased proliferation of fibrous tissue and reduced infiltration of inflammatory cells, though necrosis was still present compared with the rats without curcumin treatment. The immunohistochemical assay demonstrated that curcumin treatment inhibited the expression of NF- $\kappa \mathrm{B}$, but increased the expression of PPAR $-\gamma$. The results of the reverse transcription-polymerase chain reaction indicated that curcumin treatment significantly increased the mRNA expression levels of $\mathrm{Bcl}-2(\mathrm{P}<0.01)$. Therefore, curcumin antagonizes cardiomyocyte apoptosis and inhibits inflammatory cell infiltration following myocardial infarction, which may be associated with its inhibitory effects on the expression of $\mathrm{NF}-\kappa \mathrm{B}$,
\end{abstract}

Correspondence to: Professor Feng-Hua Lv, Department of Cardiology, The First Teaching Hospital of Xinxiang Medical College, 88 Jiankang Road, Weihui, Henan 453100, P.R. China E-mail: doctorlvfh@163.com

Key words: curcumin, myocardial infarction, nuclear factor- $\kappa \mathrm{B}$, peroxisome proliferator-activated receptor- $\gamma$, B-cell leukemia/lymphoma-2 and activating effects on the expression of PPAR- $\gamma$ and Bcl-2 in myocardial cells. Curcumin may be useful in clinical practice for saving more living heart muscle in the area of myocardial infarction and improving cardiac function following the elective opening of obstructed coronary arteries.

\section{Introduction}

Myocardial infarction leads to the production of a large number of oxygen free radicals which damage myocardial tissues and induce myocardial apoptosis and inflammation. The resulting compensatory hypertrophy and fibrosis of the surviving myocardium and extracellular matrix deposition leads to left ventricular dysfunction with subsequent heart failure $(1,2)$. Curcumin is a small natural polyphenol compound found in tumeric, which is a spice derived from the rhizomes of the plant Curcuma longa Linn. Commercially available curcumin is usually a mixture containing curcumin, hexahydrocurcumin, demethoxycurcumin and bisdemethoxycurcumin, in which curcumin accounts for $>70 \%$ of the total mixture and serves as the primary active ingredient.

Previous studies have indicated that curcumin exerts cardioprotective effects in patients and animal models with acute or chronic myocardial infarction (3-6). In particular, a previous clinical study demonstrated that curcumin was able to decrease the incidence of in-hospital myocardial infarction from $30 \%$ (placebo) to $13.1 \%$ in the patients following coronary artery by decreasing $\mathrm{C}$-reactive protein, malondialdehyde and $\mathrm{N}$-terminal pro-B-type natriuretic peptide levels (3). Animal studies have also demonstrated that curcumin promotes cardiac injury, limits myocardial infarction and improves cardiac function following acute and chronic myocardial ischemia (4-6). It is currently thought that the antioxidant and anti-inflammatory effects of curcumin account for its cardioprotective effects $(5,6)$; however, the detailed mechanisms remain unclear.

In the current study, a myocardial infarction rat model was established by ligation of the left anterior descending coronary artery via thoracotomy. Curcumin was then provided by intragastric administration to the model rats for 4 weeks. Then, the histopathological changes to the infarction area, 
the apoptosis levels in the myocardial infarction area, and the effects of curcumin on nuclear factor $-\kappa \mathrm{B}(\mathrm{NF}-\kappa \mathrm{B})$, peroxisome proliferator-activated receptor- $\gamma$ (PPAR- $\gamma)$ and B-cell leukemia/lymphoma-2 (Bcl-2) mRNA expression following myocardial infarction were examined. The aim of the present study was to reveal the effects of curcumin on the myocardium following myocardial infarction, as well as the possible protective mechanism underlying these effects. The results of this study may justify the practice of elective opening of the occluded blood vessels to improve cardiac function.

\section{Materials and methods}

Animals. A total of 32 healthy Sprague-Dawley rats (weight, $180 \pm 10 \mathrm{~g}$ ), including 16 males and 16 females, were randomly assigned to a blank control group $(n=8)$, a sham-operation group $(n=8)$ and an operation group $(n=16)$. The animals were provided by the Experimental Animal Center of Xinxiang Medical College (Xinxiang, China) and bred in experimental animal rooms of the Xinxiang Medical University Forensic Laboratory with good ventilation, natural light and a normal circadian cycle. The indoor temperature was maintained at $21-27^{\circ} \mathrm{C}$. The animals were maintained and experiments were conducted in accordance with the Institutional Animal Care and Use guidelines.

Preparation of the myocardial infarction model. The rats were acclimatized for a week as previously outlined by Lv et al (7) and $\mathrm{Ng}$ and Kamm (8). A rat myocardial infarction model was established by ligation of the left anterior descending coronary artery via thoracotomy. Briefly, the rats were anesthetized by intraperitoneal injection of $10 \%$ chloral hydrate (0.3 ml/100 g; Dalian Meiun Biotech Co., Ltd., Dalian, China). Electrocardiogram (ECG) lead II tracing was recorded when respiration and cardiac rhythm were stabilized (Fig. 1). The skin in the middle of the neck was incised vertically $\sim 1 \mathrm{~cm}$ in length. The trachea was exposed by separating the subcutaneous tissue from the neck muscles. A thread was inserted below the trachea to fix the endotracheal cannula. The endotracheal cannula was placed at the level of the third or fourth cricoid cartilage following transverse incision of the trachea, and connected with an animal ventilator to assist breathing. An incision of $\sim 5 \mathrm{~cm}$ in length was made to the center of chest. The intercostal muscles were bluntly dissected at the level of the 3-4 intercostal space. The heart was visualized after the pericardium was pulled apart. Using the great cardiac vein as a marker, a needle was inserted from a point $\sim 2 \mathrm{~mm}$ below the left atrial appendage and $\sim 2 \mathrm{~mm}$ in depth. The needle exited between the pulmonary conus and left atrial appendage. The skin incision was sutured and the heart immediately restored. The color change and movement of the left ventricular myocardium were observed. The myocardial infarction model was considered successful when the left ventricle showed signs of cyanosis and reduced wall movement, and ST segment or T-wave elevation was observed (Fig. 2). Pleural effusion was drained and the chest wall was closed. The ventilator was eliminated following waking of the rats from the anesthetic. The thread was loosely tied between the pulmonary conus and the left atrial appendage without tight ligation for the rats in the sham-operation group. The rats in blank control group received no treatment. The rats were subsequently closely observed and managed if necessary following the surgical procedure in order to improve the survival rate of the animals.

Administration of curcumin. A total of $24 \mathrm{~h}$ after the surgical procedure, the 16 surviving rats in the operation group were randomized to a myocardial infarction group $(n=8)$ and curcumin group $(n=8)$. The rats in the curcumin group were treated with intragastric administration of $150 \mathrm{mg} / \mathrm{kg} /$ body weight curcumin (Sinopharm Chemical Reagent Co., Ltd., Shanghai, China) once a day, as previously described (5). The rats in the other groups were given distilled water of the same volume.

Sample processing. A total of 4 weeks after intragastric administration, the rats were anesthetized. Myocardial tissue samples were obtained from each rat and divided into two sample sets. The general appearance of the heart of the rats in the sham-operation group was similar to that of the blank control group. Tissue samples were obtained within $2 \mathrm{~mm}$ of the infarction area prior to being rinsed with saline. A sample of tissue was placed in $4 \%$ paraformaldehyde solution and embedded in paraffin. Another sample of tissue was frozen at $-80^{\circ} \mathrm{C}$ in a refrigerator for future extraction of tissue mRNA.

Hematoxylin and eosin $(H \& E)$ staining. Myocardial tissues were embedded in paraffin and $5-\mu \mathrm{m}$ sections were subsequently prepared. Sections were deparaffinized, rehydrated and stained with H\&E as previously described (9) and visualized under a light microscope (magnification, x400).

Terminal deoxyribonucleotidyl transferase-mediated dUTP-biotin nick end-labeling (TUNEL) staining. Myocardial slices were deparaffinized and rehydrated as previously mentioned. The apoptosis of myocytes was assessed by a TUNEL apoptosis kit (Roche Diagnostics, Basel, Switzerland) according to the manufacturer's instructions.

Immunohistological staining. Myocardial slices were prepared as previously mentioned. Slices were treated with citrate buffer at $98^{\circ} \mathrm{C}$ for 20 min. Following blocking with $10 \%$ goat serum at $37^{\circ} \mathrm{C}$ for $15 \mathrm{~min}$, the slices were incubated with rabbit anti-PPAR- $\gamma$ polyclonal antibody (Peprotech Inc., Rocky Hill, NJ, USA; 1:200) or rabbit anti-NF- $\kappa$ Bp6 polyclonal antibody (Peprotech Inc.; 1:100) at $4^{\circ} \mathrm{C}$ overnight. Following washing with PBS three times, the slices were incubated with biotin-labeled goat anti-rabbit IgG solution (Beijing Zhongshan Golden Bridge Biotechnology Co., Ltd., Beijing, China) at $37^{\circ}$ for $30 \mathrm{~min}$, and then washed with PBS three times. Slices were subsequently incubated with horseradish peroxidase-conjugated streptavidin (Beijing Zhongshan Golden Bridge Biotechnology Co., Ltd.) and DAB solution (Beijing Zhongshan Golden Bridge Biotechnology Co., Ltd.). Motic Images Advanced 3.2 software was used for band detection, image capture and quantification.

Reverse transcription-polymerase chain reaction (RT-PCR) analysis. Total RNA was extracted from myocardial tissues using a Biozol RNA Extraction kit (Biomiga Inc., San Diego, CA, USA), as per the manufacturer's instructions. Tissues were harvested from the left ventricles, $2 \mathrm{~mm}$ in from of the border zones. Prior to the RT and PCR transcription reactions, total RNA was treated with DNase I (Thermo Fisher Scientific, 
Inc.; cat no: AM2222) to remove the genomic DNA. A total of $1 \mu \mathrm{g}$ RNA was used to synthesize cDNA with a BioRT Reverse Transcription kit (Hangzhou Bioer Technology Co., Ltd., Hangzhou, China; cat no: KIT0315), and 100 ng cDNA was subsequently used for the RT-PCR reaction with an RT-PCR kit (Hangzhou Bioer Technology Co., Ltd.; cat no: 402876), according to the manufacturer's instructions. PCR products were separated by electrophoresis with $1.5 \%$ agarose gel and visualized using ethidium bromide (Shang Hai Haoran Biological Technology Co., Shanghai, China; Ltd., cat no: 1203-10) on a UV transilluminator (Shanghai Clinx Science Instruments, Shanghai, China). DNA markers were provided by Takara Biotechnology Co., Ltd. (Beijing, China). Bcl2 and $\beta$-actin primers were synthesized by Shanghai Sun Biotech Co. Ltd. (Shanghai, China) and their sequences were as follows: Bcl2, forward 5'-CCGCTACCGTCCGATACTTCA-3' and reverse 5'-AAGACACAGAGGCCGCATGCTTG-3'; and $\beta$-actin, forward 5'-CAGATACAGCTCGCCTAGAAG-3' and reverse 5'-GATTGACTGCTCTGCTCCTCA-3'. DNA marker was provided by Takara Biotechnology Co., Ltd. (Beijing, China). Relative expression of Bcl-2 was calculated by quantifying the gray scale values of the target gene expression, relative to $\beta$-actin, which performed using ImageJ software (National Institutes of Health, Bethesda, MD, USA).

Imaging and statistical analysis. Motic Images Advanced version 3.2 software (Motic China Group Co., Ltd., Xiamen, China), Gene Tools (Gene Tools, LLC, Philomath, OR, USA) and SPSS 17.0 (SPSS, Inc., Chicago, IL, USA) for Windows were used to analyze immunohistochemical images, RT-PCR results, and data sets, respectively. The measurement data were presented as means \pm standard deviation and tested for normality and homogeneity of variance. The data were subjected to analysis of variance by group if applicable. A least significant difference $t$-test was used for further pairwise comparison. If the data were not applicable for analysis of variance, they were converted accordingly and then tested by analysis of variance. If heterogeneity of variance and/or non-normal distribution was still present, Kruskal-Wallis rank sum test was used to compare the data. All the hypothesis tests were two-sided. $\mathrm{P}<0.05$ was considered to indicate a statistically significant difference.

\section{Results}

Morphological results for the left ventricular cardiomyocytes of the rats. Following hematoxylin and eosin staining, the myocardial cells of the left ventricle of the rats in the blank control group (Fig. 3) and sham-operation group (Fig. 4) were cylindrical, parallel to each other and in orderly patterns under a light microscope. The cells were not damaged in structure with oval nuclei located in the center. The transverse striation was clearly observable. There was no necrotic or apoptotic cells but some white blood cells were visible. For the myocardial infarction group (Fig. 5) and curcumin group (Fig. 6), the left ventricular wall was pale and thin, with left ventricular bulging. The cells at the infarction zone of the left ventricle were shrunken with hyperchromatic cytoplasm, lysis and breakage of myocardial fibers, and karyopyknosis and karyorrhexis. Infiltration of inflammatory cells

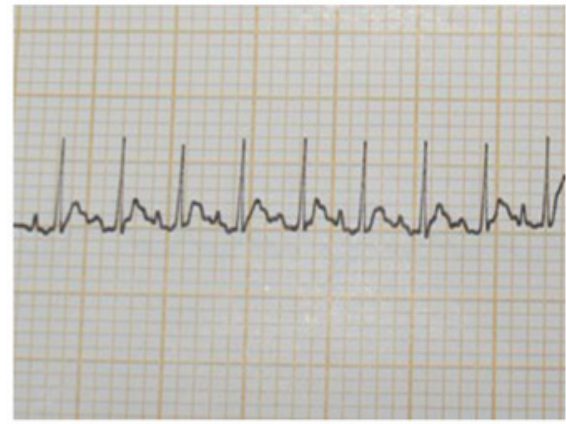

Figure 1. Normal electrocardiogram $25 \mathrm{~mm} / \mathrm{s} 10 \mathrm{~mm} / \mathrm{mV}$

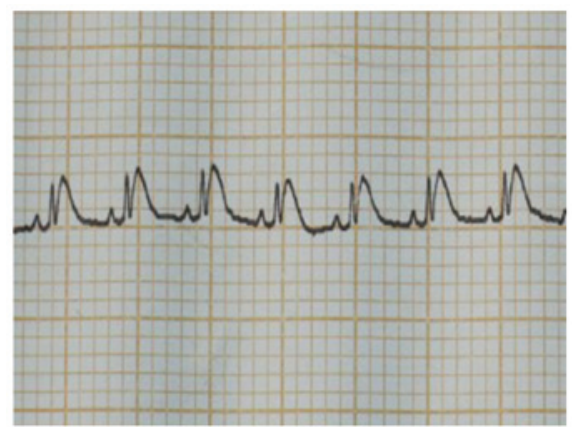

Figure 2. Myocardial infarction electrocardiogram $25 \mathrm{~mm} / \mathrm{s} 10 \mathrm{~mm} / \mathrm{mV}$.

and increased fibroblasts and fiber components were also observed. Compared with the myocardial infarction group, necrotic myocardial cells were still observed in the curcumin group (Fig. 6), although fibroplasia at the infarction site and inflammatory cell infiltration were improved.

Myocardial apoptosis as determined by TUNEL. The cells with tan myocardial nuclei were considered apoptotic cells. The nuclei of myocardial cells from the rats in the blank control group (Fig. 7) and sham-operation group (Fig. 8) were blue with almost no evidence of apoptosis. The apoptosis index did not indicate significant difference between the two groups $(\mathrm{P}>0.05)$. Four weeks after myocardial infarction, the cells surrounding the infarction area were predominantly apoptotic cells in the myocardial infarction group (Fig. 9). The difference was statistically significant $(\mathrm{P}<0.001)$ compared with the blank control or sham-operation group. The number of apoptotic cells in the curcumin group (Fig. 10) was lower, as compared with those in the myocardial infarction group. The difference in the apoptosis index was statistically significant $(\mathrm{P}<0.001)$, although the number of apoptotic cells remained higher than in the blank control or sham-operation group $(\mathrm{P}<0.001$; Table I).

Immunohistochemical analysis of $N F-\kappa B p 65$ and PPAR- $\gamma$ proteins. The result was considered positive if the immunohistochemical analysis demonstrated the presence of brown particles under microscopic analysis. Low levels of NF-кBp65 expression were observed in the cytoplasm in both the blank control group and the sham-operation group. No significant difference was observed between these two groups $(\mathrm{P}>0.05)$. $\mathrm{NF}-\kappa \mathrm{Bp} 65$ expression in both the nucleus and cytoplasm 


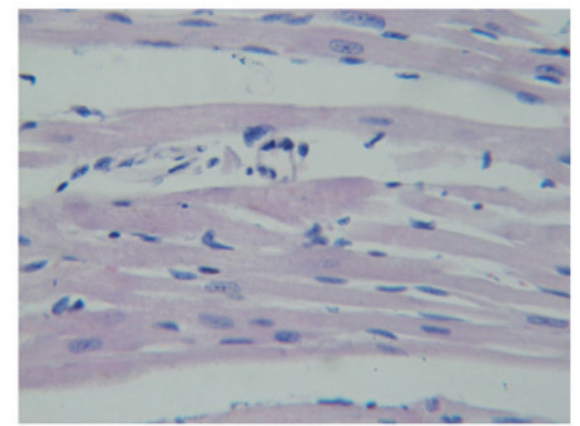

Figure 3. Hematoxylin and eosin staining in the control group. Magnification, $\mathrm{x} 400$

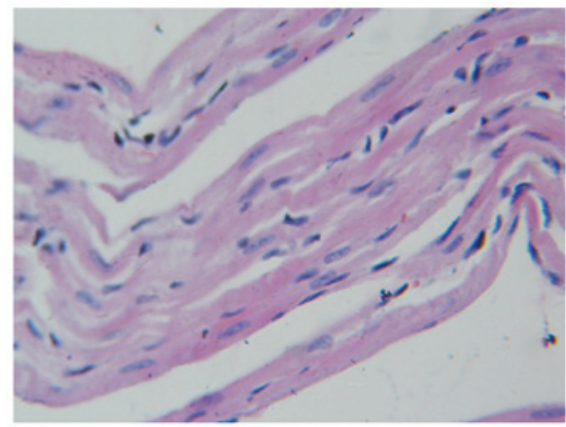

Figure 4. Hematoxylin and eosin staining in the sham-operation group. Magnification, $\mathrm{x} 400$.

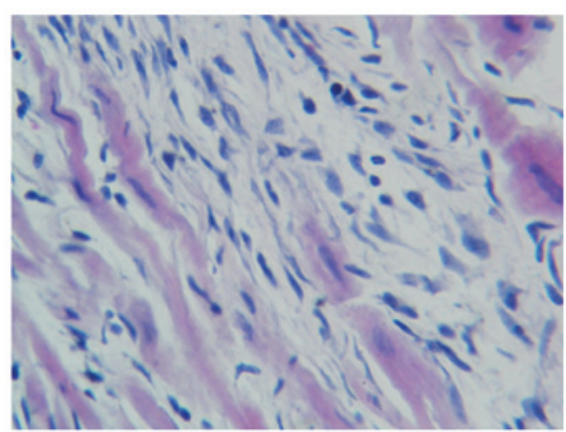

Figure 5. Hematoxylin and eosin staining in the myocardial infarction group. Magnification, $\mathrm{x} 400$.

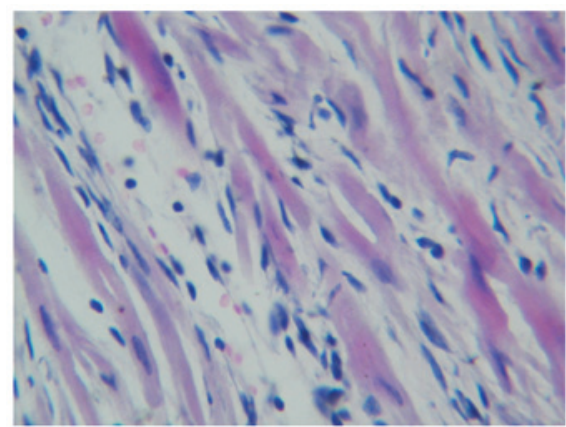

Figure 6. Hematoxylin and eosin staining in the curcumin group Magnification, $\mathrm{x} 400$.

(especially the nucleus) increased significantly in the myocardial infarction group, as compared with the curcumin group

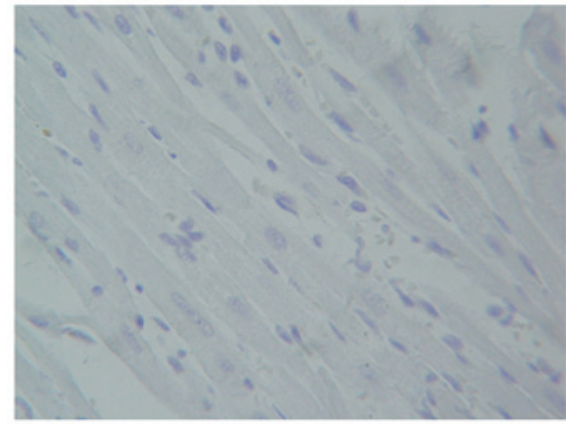

Figure 7. TUNEL of the control group. Magnification, $\mathrm{x} 400$.

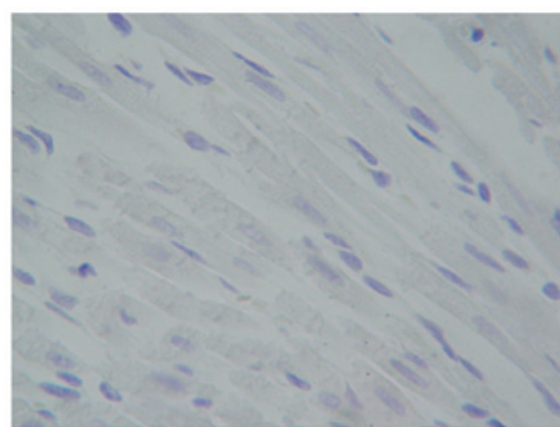

Figure 8. TUNEL of the sham-operation group. Magnification, $\mathrm{x} 400$.

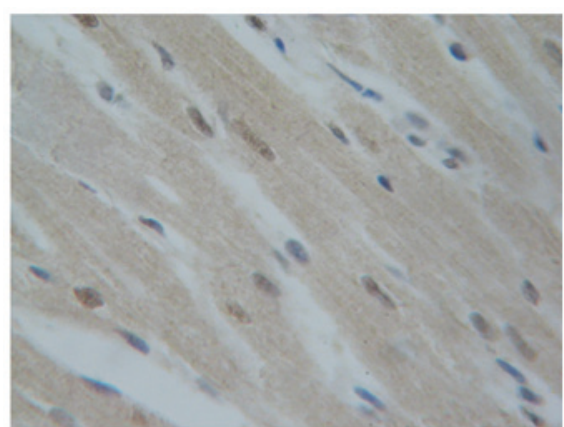

Figure 9. TUNEL of the myocardial infarction group. Magnification, $\mathrm{x} 400$.

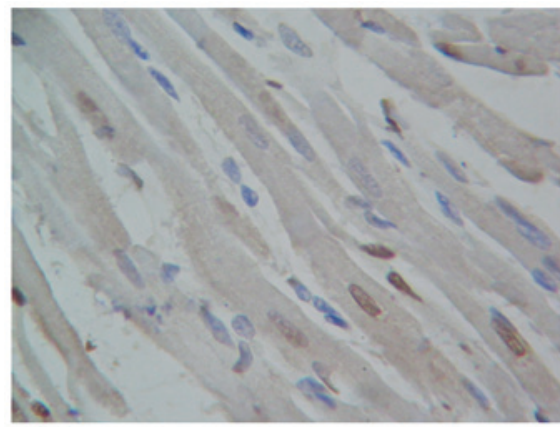

Figure 10. TUNEL of the curcumin group. Magnification, $x 400$.

$(\mathrm{P}<0.01)$. The expression of NF- $\mathrm{kBp} 65$ in the curcumin group was significantly lower than that in the myocardial infarction group, but remained higher compared with that of the blank control or sham-operation groups ( $\mathrm{P}<0.01$; Figs. 11-14; Table II). 
Table I. Apoptosis index of the myocardial cells of rats in each group (mean \pm standard deviation).

\begin{tabular}{lcc}
\hline Group & $\mathrm{n}$ & Apoptosis index $(\%)$ \\
\hline Blank control & 6 & $1.881 \pm 0.921$ \\
Sham-operation & 6 & $0.979 \pm 0.811^{\mathrm{a}}$ \\
Myocardial infarction & 6 & $38.383 \pm 3.880^{\mathrm{b}, \mathrm{c}}$ \\
Curcumin $(150 \mathrm{mg} / \mathrm{kg} \cdot \mathrm{d})$ & 6 & $15.153 \pm 1.175^{\mathrm{b}, \mathrm{c}, \mathrm{d}}$ \\
F-value & & 500.280
\end{tabular}

${ }^{\mathrm{a}}>0.05$ and ${ }^{\mathrm{b}} \mathrm{P}<0.001$, vs. the blank control. ${ }^{\mathrm{C}} \mathrm{P}<0.001$, vs. the sham-operation. ${ }^{\mathrm{d}} \mathrm{P}<0.001$, vs. myocardial infarction.

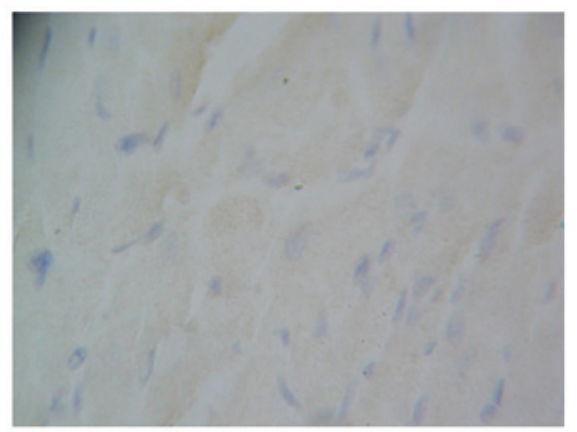

Figure 11. Expression of nuclear factor- $\mathrm{\kappa} B$ in the control group. Magnification, $\mathrm{x} 400$.

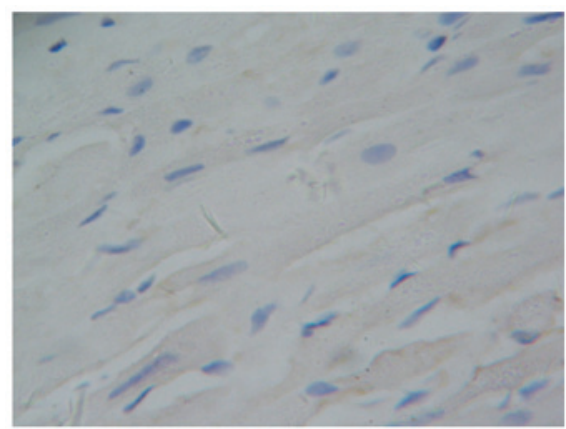

Figure 12. Expression of nuclear factor- $\mathrm{\kappa} B$ in the sham-operation group. Magnification, $\mathrm{x} 400$.

Low expression levels of PPAR- $\gamma$ were observed in the nucleus of both the blank control and sham-operation groups. There was no significant difference between these two groups $(\mathrm{P}>0.05)$. PPAR- $\gamma$ expression in the myocardial infarction group was higher compared with that in blank control or sham-operation group, although this difference was not statistically significant $(P>0.05)$. Notably, the levels of PPAR- $\gamma$ expression in the nucleus were higher in the curcumin group, compared with those in the blank control, sham-operation or myocardial infarction groups. This difference was statistically significant $(\mathrm{P}<0.01$; Figs. $15-18$; Table II).

mRNA expression levels of Bcl-2. RT-PCR results demonstrated that Bcl-2 mRNA expression levels were not

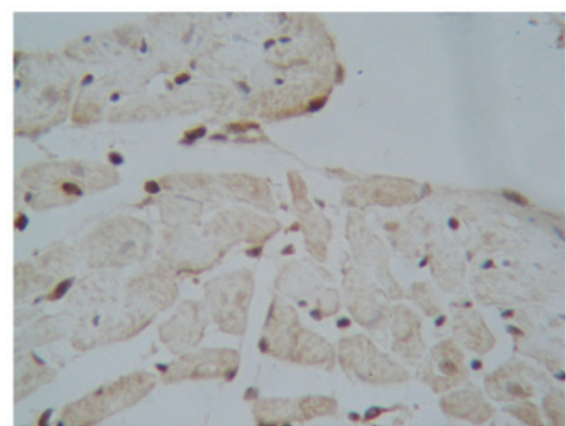

Figure 13. Expression of nuclear factor- $\mathrm{\kappa B}$ in the myocardial infarction group. Magnification, x400.

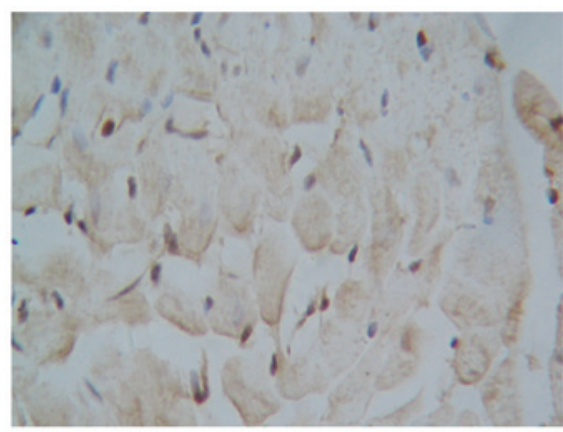

Figure 14. Expression of nuclear factor- $\kappa \mathrm{B}$ in the curcumin group. Magnification, $\mathrm{x} 400$.

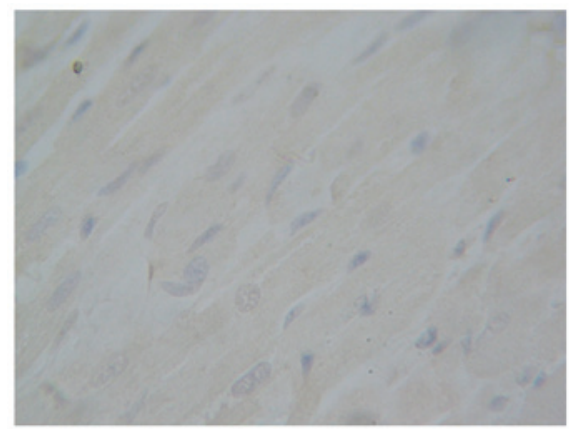

Figure 15. Expression of proliferator-activated receptor- $\gamma$ in the control group. Magnification, $\mathrm{x} 400$.

significantly different between the blank control and sham-operation group $(\mathrm{P}>0.05)$. The mRNA expression levels of Bcl-2 in the myocardial infarction group were significantly lower compared with those of the blank control or sham-operation group $(\mathrm{P}<0.01)$. Bcl-2 mRNA expression levels in the curcumin group were significantly higher compared with those in the myocardial infarction group $(\mathrm{P}<0.01)$ but remained lower compared with those of the blank control or sham-operation group $(\mathrm{P}<0.01$; Fig. 19, Table III).

\section{Discussion}

Myocardial infarction is associated with necrosis and apoptosis which induces dysfunction of tissues and organs. 
Table II. Optical density of NF- $\kappa \mathrm{B}$ and PPAR- $\gamma$ protein expression in the cardiomyocytes of rats (mean \pm standard deviation).

\begin{tabular}{lccc}
\hline Group & $\mathrm{N}$ & $\mathrm{NF}-\kappa \mathrm{Bp} 65$ & PPAR- $\gamma$ \\
\hline Blank control & 6 & $0.173 \pm 0.010$ & $0.101 \pm 0.007$ \\
Sham-operation & 6 & $0.166 \pm 0.008^{\mathrm{a}}$ & $0.101 \pm 0.005^{\mathrm{e}}$ \\
Myocardial infarction & 6 & $0.325 \pm 0.004^{\mathrm{b}, \mathrm{c}}$ & $0.107 \pm 0.006^{\mathrm{e}, \mathrm{f}}$ \\
Curcumin $(150 \mathrm{mg} / \mathrm{kg})$ & 6 & $0.275 \pm 0.010^{\mathrm{b}, \mathrm{c}, \mathrm{d}}$ & $0.131 \pm 0.019^{\mathrm{g}, \mathrm{h}}$ \\
F-value & & 585.431 & 411.149 \\
\hline
\end{tabular}

${ }^{\mathrm{a}} \mathrm{P}>0.05$ and ${ }^{\mathrm{b}} \mathrm{P}<0.01$, vs. the blank control; ${ }^{\mathrm{c}} \mathrm{P}<0.01$, vs. the sham-operation; ${ }^{\mathrm{d}} \mathrm{P}<0.01$, vs. myocardial infarction; ${ }^{\mathrm{e}} \mathrm{P}>0.05$, vs. the blank control; ${ }^{\mathrm{f}} \mathrm{P}>0.05$, vs. the sham-operation; ${ }^{\mathrm{g}} \mathrm{P}<0.01$, vs. the blank control; ${ }^{\mathrm{h}} \mathrm{P}<0.01$, vs. the sham-operation.

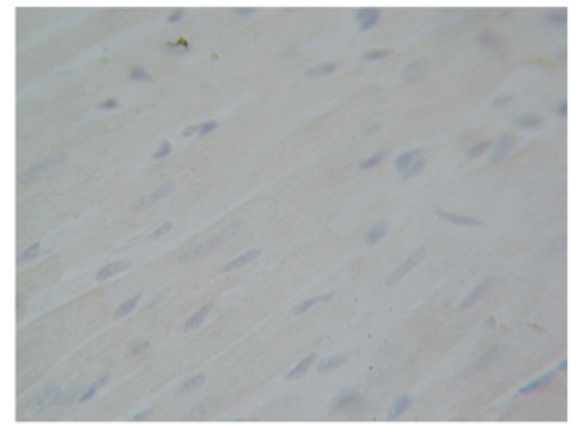

Figure 16.Expression of proliferator-activated receptor- $\gamma$ in the sham-operation group. Magnification, x400.

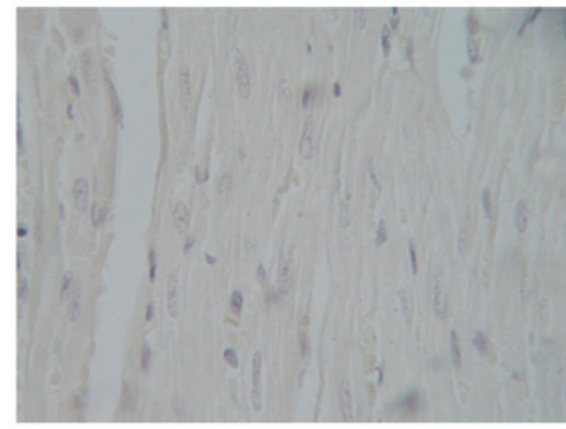

Figure 17. Expression of proliferator-activated receptor- $\gamma$ in the myocardial infarction group. Magnification, $\mathrm{x} 400$.

Persistent apoptosis leads to the progressive loss of cells, which is known to be an important cause for myocardial fibrosis, ventricular dilation, cardiac remodeling, gradual decrease of cardiac function and heart failure following myocardial infarction $(10,11)$. Therefore, inhibition of apoptosis following myocardial infarction and protecting myocardial cells against loss has become an important focus (12). A critical aspect of cardiovascular research is the development of novel drugs and the investigation of the effects of existing drugs on the protection of the ischemic myocardium, the promotion of myocardial angiogenesis, and the improvement of cardiac remodeling and function following myocardial infarction.

Curcumin is a widely used drug that has been the subject of investigation in the field of cardiovascular research (13). The principal functions of curcumin include: i) Anti-inflammation: Curcumin functions in alleviating the pain induced by inflam-

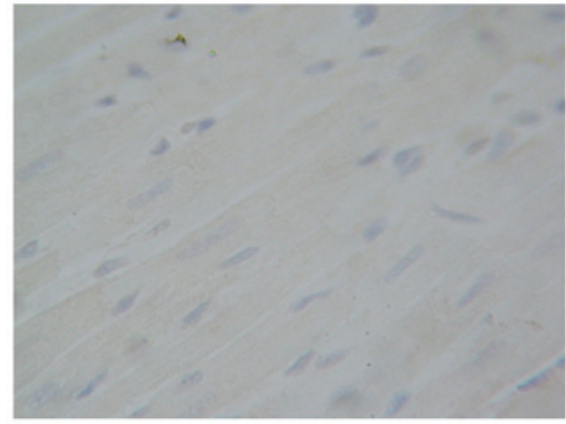

Figure 18. Expression of proliferator-activated receptor- $\gamma$ in the curcumin group. Magnification, $\mathrm{x} 400$.

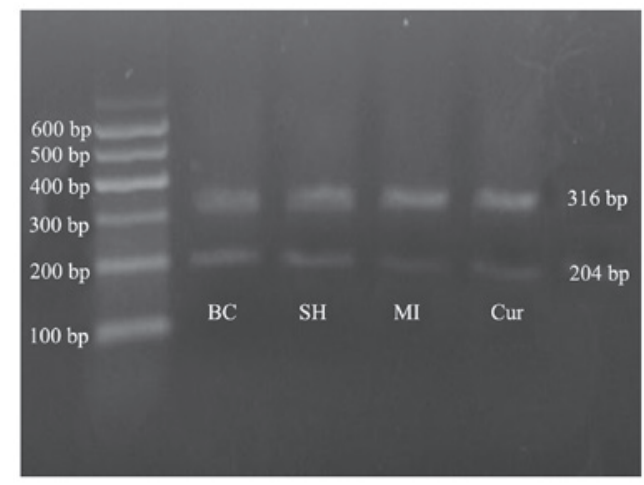

Figure 19. B cell lymphoma-2 mRNA/ $\beta$-actin expression in each group. BC blank control group; $\mathrm{SH}$, sham-operation group; $\mathrm{MI}$, myocardial infarction group; Cur, curcumin group.

mation predominantly by activating inflammatory mediators such as lipoxygenase and cyclooxygenase, and transcription factors such as activator protein-1 $(14,15)$; ii) antioxidant: There are two benzene rings in the chemical structure of curcumin, with one ring having a phenol hydroxy and the other a phenol methoxy. These are able to eliminate oxygen free radicals, serve as hydrogen donors or adjust other mediators involved in the oxidation reaction against antioxidant and anti-lipid peroxidation; iii) regulation of blood lipids: Curcumin may lower the level of total cholesterol, triglyceride and low density lipoprotein, increase the level of high-density lipoprotein, inhibit the oxidative modification of low density lipoprotein (16), and reduce the damage to the vessel walls by oxidized low density lipoprotein; iv) curcumin may also reduce myocardial ischemia 
Table III. Bcl-2 mRNA/ $\beta$-actin gray scale values of myocardial tissues of rats (mean \pm standard deviation).

\begin{tabular}{lcc}
\hline Group & $\mathrm{N}$ & Bcl-2 mRNA $/ \beta$-actin \\
\hline Blank control & 6 & $0.519 \pm 0.024$ \\
Sham-operation & 6 & $0.499 \pm 0.023^{\mathrm{a}}$ \\
Myocardial infarction & 6 & $0.234 \pm 0.018^{\mathrm{b}, \mathrm{c}}$ \\
Curcumin $(150 \mathrm{mg} / \mathrm{kg})$ & 6 & $0.341 \pm 0.019^{\mathrm{b}, \mathrm{c}, \mathrm{d}}$ \\
F value & & 271.827 \\
\hline
\end{tabular}

${ }^{\mathrm{a}} \mathrm{P}>0.05$ and ${ }^{\mathrm{b}} \mathrm{P}<0.01$, vs. blank control. ${ }^{\mathrm{c}} \mathrm{P}<0.01$, vs. sham-operation. ${ }^{\mathrm{d}} \mathrm{P}<0.01$, vs. myocardial infarction.

re-perfusion injury (17), lower blood viscosity, inhibit the formation of atherosclerotic plaque, stabilize plaque and inhibit adaptive hypertrophy $(18,19)$ of the myocardium following myocardial infarction.

The results of the present study demonstrated that following four weeks of administration of curcumin, the left ventricular myocardium of rats in the myocardial infarction group and curcumin-treated group turned pale and the walls grew thin. The ventricular wall of the rats in the myocardial infarction group bulged. Cells at the infarction area were atrophic associated with hyperchromatic cytoplasm, lysis and breakage of myocardial fiber, karyopyknosis and karyorrhexis, infiltration of inflammatory cells and increasing fibroblasts. Compared with the myocardial infarction group, broken myocardial cells were also observed in the curcumin group, although there were more living myocardial cells, and fiber hyperplasia at the infarction area and inflammatory cell infiltration decreased. An increased number of apoptotic cells was observed surrounding the infarction area in the myocardial infarction group, which is consistent with the results of a previous study (19). The apoptotic cells surrounding the infarction area of the curcumin group decreased significantly, which indicates that curcumin is able to inhibit the apoptosis of myocardial cells following myocardial infarction, thereby protecting the myocardium.

The increase in cell apoptosis is an important pathological process following myocardial infarction. $\mathrm{Bcl}-2$ is an important anti-apoptotic factor, which is able to inhibit the apoptosis induced by various factors, including Bcl-X1 and Bax, and enhance the resistance of cells to DNA damage, increasing cell survival (20). The results of the present study demonstrated that Bcl-2 mRNA expression decreased in the myocardial infarction group, whereas Bcl-2 expression in the curcumin group ( $150 \mathrm{mg} / \mathrm{kg} /$ body weight) increased significantly compared with the myocardial infarction group due to the effect of curcumin. These results suggest that curcumin is able to increase $\mathrm{Bcl}-2 \mathrm{mRNA}$ expression, thereby inhibiting the apoptosis of myocardial cells.

NF- $\kappa \mathrm{B}$ is a regulatory factor that controls the transcription of DNA; it is a key nuclear transcription factor that has important functions in signaling. NF- $\mathrm{kB}$ is involved in gene expression and regulation, including the development of immunity, inflammation, and tumor development. The activation of $\mathrm{NF}-\kappa \mathrm{B}$ leads to the expression of various target genes, thereby promoting cell proliferation and inhibiting apoptosis (21). Apoptosis is regulated by numerous genes, among which Bcl-2, an anti-apoptosis gene, is a proto-oncogene closely associated with apoptosis and a key downstream target gene of NF- $\kappa B(20)$. When NF- $\kappa B$ associates with a stimulating factor, it dissociates from its inhibition protein ІкB and becomes activated, following which it translocates to the nucleus (22). Transcription and translation of the downstream target genes in the nucleus are subsequently activated to regulate inflammatory responses, tissue injury, oxidative stress, cell differentiation, tissue proliferation and apoptosis (23). Therefore, regulating the effects of NF- $\mathrm{kB}$ effectively influences the physiology and pathophysiology of the above-mentioned processes. In the present report, increased infiltration of inflammatory cells at the infarction area was observed in the myocardial infarction group. NF- $\kappa \mathrm{B}$ expression levels (predominantly located in the nucleus) were significantly higher compared with those of the blank control or sham-operation group. In other words, NF- $\mathrm{KB}$ was activated due to myocardial infarction. The rats in the curcumin group ( $150 \mathrm{mg} / \mathrm{kg} /$ body weight) were treated with curcumin for four weeks. The infiltrated inflammatory cells were significantly reduced and the protein expression levels of NF- $\kappa \mathrm{B}$ decreased significantly compared with myocardial infarction group.

PPAR- $\gamma$ inhibits inflammation via the NF- $\kappa B$-mediated signal transduction pathway, and mitigates cell damage by reducing the levels of oxygen radicals released by neutrophils (24). Activated PPAR- $\gamma$ is likely to promote the regeneration of myocardial cells in the infarction area. PPAR- $\gamma$ is not only involved in fat formation, lipid and glucose metabolism, but also has an important impact on vascular biology and inflammatory response, especially in the pathogenesis of atherosclerosis (25). PPAR- $\gamma$ protects the vascular endothelium, regulates inflammatory cytokines and the expression of adhesion molecules on the cell surface, inhibits macrophage activation, promotes the reverse transport of cholesterol, inhibits proliferation of vascular smooth muscle cell and stabilizes the atherosclerotic plaque $(7,26)$. The results showed the presence of low PPAR- $\gamma$ expression in the myocardial tissue samples of both the blank control group and the sham-operation group. PPAR- $\gamma$ expression in the curcumin group $(150 \mathrm{mg} / \mathrm{kg} /$ body weight) increased significantly, which indicates that curcumin is able to promote PPAR- $\gamma$ expression, thereby making it possible to protect the myocardium by stimulating the transcription of genes downstream of PPAR- $\gamma$.

In conclusion, curcumin has a protective effect on ischemic and hypoxic myocardium by increasing Bcl-2 and PPAR- $\gamma$ expression, inhibiting apoptosis and NF- $\mathrm{\kappa B}$ expression, and reducing inflammation. Curcumin is specifically indicated for patients whose coronary artery cannot be opened through an emergency surgical procedure. PCI may be provided to open the occluded blood vessels following remission of acute disease or when appropriate to activate the hibernating (contractile dysfunction) or stunned (transient ischemia) myocardium, slow ventricular remodeling, and improve and enhance heart function. Therefore, it remains important to implement revascularization surgery on the basis of pharmacotherapy in clinical practice. The results of the present study provide a preliminary investigation into the inhibition of myocardial cell necrosis and apoptosis. Further clinical research on the 
protective effects of curcumin on human ischemic myocardial cells is required.

\section{Acknowledgements}

The present study was supported by the Henan Funding Program for College Young Backbone Teachers (grant no. 2009GGJS-085).

\section{References}

1. Qipshidze N, Metreveli N, Mishra PK, Lominadze D and Tyagi SC: Hydrogen sulfide mitigates cardiac remodeling during myocardial infarction via improvement of angiogenesis. Int J Bio Sci 8: 430-441, 2012.

2. Tuzun E, Bick R, Kadipasaoglu C, Conger JL, Poindexter BJ, Gregoric ID, Frazier OH, Towbin JA and Radovancevic B Modification of a volume-overload heart failure model to track myocardial remodeling and device-related reverse remodeling. ISRN Cardiol 2011: 831062, 2011.

3. Wongcharoen W, Jai-Aue S, Phrommintikul A, Nawarawong W, Woragidpoonpol S, Tepsuwan T, Sukonthasarn A, Apaijai N and Chattipakorn N: Effects of curcuminoids on frequency of acute myocardial infarction after coronary artery bypass grafting. Am J Cardiol 110: 40-44, 2012.

4. Jeong CW, Yoo KY, Lee SH, Jeong HJ, Lee CS and Kim SJ: Curcumin protects against regional myocardial ischemia/reperfusion injury through activation of RISK/GSK-3 $\beta$ and inhibition of p38 MAPK and JNK. J Cardiovasc Pharmacol Ther 17: 387-394, 2012.

5. Wang NP, Wang ZF, Tootle S, Philip T and Zhao ZQ: Curcumin promotes cardiac repair and ameliorates cardiac dysfunction following myocardial infarction. Br J Pharmacol 167: 1550-1562, 2012.

6. Sunagawa Y, Sono S, Katanassaka Y, Funamoto M, Hirano S, Miyazaki Y, Hojo Y, Suzuki H, Morimoto E, Marui A, et al: Optimal dose-setting study of curcumnin for improvement of left ventricular systolic function after myocardial infarction in rats. J Pharmacol Sci 126: 329-336.

7. Lv FH, Wang YL, Kong J, et al: Effects of curcumin on expression of apoptosis-related genes in myocardial cells of rats with acute myocardial infarction. J Appl Clin Pediatr 26: 1010-1011, 2011.

8. Ng SC and Kamm MA: Therapeutic strategies for the management of ulcerative colitis. Inflamm Bowel Dis 15: 935-950, 2009.

9. Li N, Tian Y, Wang C, Zhang P and You S: Protective effect of Lai Fu Cheng Qi decoction on severe acute pancreatitis-induced myocardial injury in a rat model. Exp Ther Med 9: 1133-1140, 2015.

10. Konstantinova EV, Khomyakova NF, Konstantinova NA, Podkolzina AV and Sapozhnikov AM: Relationship between apoptosis and expression of heat shock proteins in peripheral blood lymphocytes of patients with myocardial infarction. Bull Exp Biol Med 150: 682-684, 2011.

11. Rondeau I, Picard S, Bah TM, Roy L, Godbout R and Rousseau G: Effects of different dietary $\omega-6 / 3$ polyunsaturated fatty acids ratios on infarct size and the limbic system after myocardial infarction. Can J Physiol Pharmacol 89: 169-176, 2011.
12. Lee $Y$ and Gustafsson AB: Role of apoptosis in cardiovascular disease. Apoptosis 4: 536-548, 2009.

13. Wongcharoen $\mathrm{W}$ and Phrommintikul A: The protective role of curcumin in cardiovascular diseases. Int J Cardiol 2: 145-151,2009.

14. Basnet P and Skalko-Basnet N: Curcumin: An anti-inflammatory molecule from a curry spice on the path to cancer treatment. Molecules 16: 4567-4598, 2011.

15. Han YK, Lee SH, Jeong HJ, Kim MS, Yoon MH and Kim WM: Analgesic effects of intrathecal curcumin in the rat formalin test. Korean J Pain 25: 1-6, 2012.

16. Yuan HY, Kuang SY, Zheng X, Ling HY, Yang YB, Yan PK, Li K and Liao DF: Curcumin inhibits cellular cholesterol accumulation by regulating SREBP-1/caveolin-1 signaling pathway in vascular smooth muscle cells. Acta Pharmacol Sin 29: 555-563, 2008.

17. González-Salazar A, Molina-Jijón E, Correa F, Zarco-Márquez G, Calderón-Oliver M, Tapia E, Zazueta C and Pedraza-Chaverri J: Curcumin protects from cardiac reperfusion damage by attenuation of oxidant stress and mitochondrial dysfunction. Cardiovasc Toxicol 11: 357-364, 2011.

18. Morimoto T, Sunagawa Y, Fujita M and Hasegawa K: Novel heart failure therapy targeting transcriptional pathway in cardiomyocytes by a natural compound, curcumin. Circ J 74: 1059-1066, 2010.

19. Wongcharoen W and Phrommintikul A: The protective role of curcumin in cardiovascular diseases. Int J Cardiol 133: 145-151, 2009.

20. Ola MS, Nawaz M and Ahsan H: Role of Bcl-2 family proteins and caspases in the regulation of apoptosis. Mol Cell Biochem 351: 41-58, 2011.

21. Kiefel H, Pfeifer M, Bondong S, Hazin J and Altevogt P: Linking L1CAM-mediated signaling to NF- $\kappa \mathrm{B}$ activation. Trends Mol Med 4: 178-187, 2011.

22. Oeckinghaus A, Hayden MS and Ghosh S: Crosstalk in NF-кB signaling pathways. Nat Immunol 8: 695-708, 2011.

23. Sunagawa Y, Wada H, Suzuki H, Imaizumi A, Fukuda H, Hashimoto T, Katanasaka Y, Shimatsu A, Kimura T, et al: A novel drug delivery system of oral curcumin markedly improves efficacy of treatment for heart failure after myocardial infarction in rats. Biol Pharm Bull 2: 139-144, 2012.

24. Hisada S, Shimizu K, Shiratori K and Kobayashi M: Peroxisome proliferator-activated receptor gamma ligand prevents the development of chronic pancreatitis through modulating NF-kappaB-dependent proinflammatory cytokine production and pancreatic stellate cell activation. Rocz Akad Med Bialymst 50: 142-147, 2005.

25. Ahmadian M, Suh J M, Hah N, Liddle C, Atkins AR, Downes $M$ and Evans RM: PPAR $\gamma$ signaling and metabolism: The good, the bad and the future. Nat Med 19: 557-566, 2013.

26. Lv FH, Gao JZ and Zhang JY: Role of peroxisome proliferator-activated receptor signaling pathway in mice with hyperlipidemia. Chin J Geriatr 30: 1047-1050, 2011. 